\title{
Effects of Injection Timing on Fluid Flow Characteristics of Partially Premixed Combustion Based on High-Speed Particle Image Velocimetry
}

\author{
Mohammad Izadi Najafabadi \\ Eindhoven University Of Technology \\ Slavey Tanov \\ Lund University \\ Hua Wang \\ Dantec Dynamics A/S \\ Bart Somers \\ Eindhoven University Of Technology \\ Bengt Johansson \\ King Abdullah University of Science and Technology \\ Nico Dam \\ Eindhoven University Of Technology
}

\begin{abstract}
Partially Premixed Combustion (PPC) is a promising combustion concept , based on judicious tuning of the charge stratification, to meet the increasing demands of emission legislation and to improve fuel efficiency. Longer ignition delays of PPC in comparison with conventional diesel combustion provide better fuel/air mixture which decreases soot and $\mathrm{NO}_{\mathrm{x}}$ emissions. Moreover, a proper injection timing and strategy for PPC can improve the combustion stability as a result of a higher level of fuel stratification in comparison with the Homogeneous Charge Compression Ignition (HCCI) concept. Injection timing is the major parameter with which to affect the level of fuel and combustion stratification and to control the combustion phasing and the heat release behavior. The scope of the present study is to investigate the fluid flow characteristics of PPC at different injection timings. To this end, high-speed Particle Image Velocimetry (PIV) is implemented in a light-duty optical engine to measure fluid flow characteristics, including the flow fields, mean velocity and cycle-resolved turbulence, inside the piston bowl as well as the squish region with a temporal resolution of 1 crank angle degree at $800 \mathrm{rpm}$. Two injectors, having 5 and 7 holes, were compared to see their effects on fluid flow and heat release behavior for different injection timings. Reactive and non-reactive measurements were performed to distinguish injection-driven and combustiondriven turbulence. Formation of vortices and higher turbulence levels enhance the air/fuel interaction, changing the level of fuel stratification and combustion duration. Results demonstrate clearly how turbulence level correlates with heat release behavior, and provide a quantitative dataset for validation of numerical simulations.
\end{abstract}

CITATION: Izadi Najafabadi, M., Tanov, S., Wang, H., Somers, B. et al., "Effects of Injection Timing on Fluid Flow Characteristics of Partially Premixed Combustion Based on High-Speed Particle Image Velocimetry," SAE Int. J. Engines 10(4):2017, doi:10.4271/2017-010744.

\section{INTRODUCTION}

Partially Premixed Combustion (PPC), an intermediate combustion regime between HCCI (Homogenous Charge Compression Ignition) and diffusion-controlled combustion, has received much attention during the last years as an alternative combustion concept for future internal combustion (IC) engines. Very low $\mathrm{NO}_{\mathrm{x}}$ and soot emissions coupled with high efficiency have made PPC an attractive research topic $[\underline{1}, \underline{2}, \underline{3}]$. The long ignition delay of PPC (compared with conventional diesel combustion), achieved by using gasoline-like fuels and Exhaust Gas Recirculation (EGR), increases the level of premixing and prevents the persistence of locally rich zones during combustion, resulting in low soot formation, and low temperature combustion, leading to less $\mathrm{NO}_{\mathrm{x}}$ formation $[\underline{4}, \underline{5}, \underline{6}]$. 
PPC provides better controllability compared to HCCI due to higher levels of mixture stratification (spatial inhomogeneities). This level of mixture inhomogeneity, adjustable by injection timing and injection strategy, can be used as a tool to control combustion phasing $[\underline{7}, \underline{8}]$. The mixing process is mainly governed by the injection process and is highly dependent on flow and turbulence from start of injection (SOI) till start of combustion (SOC) [9]. The outcome of this process determines the ignition timing and the combustion duration, the most important parameters to be controlled. Hence, in order to better understand mixture formation in PPC, investigating the flow structure and turbulence from injection up to combustion is an essential milestone.

Flow field measurements have been carried out in optical engines for a single point, a two-dimensional plane or a three-dimensional volume, depending on the purpose of the research. Laser Doppler Anemometry (LDA) uses the Doppler shift of scattered laser light to determine the velocity at a single point, and is implemented in optical engines to measure velocity vector at critical points, like the spark plug area in SI engines or the piston bowl area in Diesel engines $[\underline{10}$, $\underline{11}, 12]$. Particle Image Velocimetry (PIV) can be applied in an optical engine as a non-intrusive laser diagnostic technique to measure flow fields in a two-dimensional plane $[\underline{9}, \underline{13}, \underline{14}, \underline{15}]$. In this technique, a pair of images is captured over a short time interval of Mie scattered light off seeding particles which should be chosen such that they faithfully follow the flow. Velocity vector fields can later be calculated from particle displacements in the image pairs. The PIV technique can also be used for three-dimensional measurements, so-called Tomo PIV, which needs two, three or four cameras depending on the number of velocity components to be measured and the seeding density [타].

To investigate the mixing process inside the combustion chamber, single-point measurements do not provide sufficient spatial information. Three dimensional measurements (Tomo PIV), on the other hand, are significantly more expensive and time costly (from a post-processing point of view). Two-dimensional PIV can still provide global information about the mixing process if a proper plane is chosen, while it is not too expensive and much less time consuming for post-processing compared with 3D PIV. Hence, high-speed 2D PIV is employed in this study to investigate the flow and turbulence structures during mixing and combustion.

For PPC regimes, PIV has been used to measure the 2D in-cylinder flow structures $[\underline{9}, \underline{13}, \underline{14}, \underline{15}, \underline{17}]$. One of the first studies was conducted by Miles et al. [1ㅡㄹ, who measured vertical plane velocity fields inside the piston bowl and the squish region of a light duty (LD) optical engine (Volvo D5). They describe the bulk flow structures, and investigate the mixing process and the formation of emissions. The measured velocity fields also indicate the locations of heat release [14]. However, their PIV measurements were carried out with a low repetition rate of $10 \mathrm{~Hz}$. Consequently, the turbulence behavior, as an important parameter which affects the mixing process, was not measured in itself (mixed with cycle-to-cycle variations). High-speed PIV gives the opportunity to measure cycle-resolved turbulence. One of the first high-speed PIV measurements $(3 \mathrm{kHz})$ of the PPC mixing process was performed by Zegers et al. [15], who studied flow structure in a horizontal plane close to the cylinder head of a heavy-duty (HD) optical engine. Their measurements concerned non-reactive conditions to see the effects of injection timings and strategies on the flow field. High-speed PIV was recently implemented by Wang et al. [9] and Tanov et al. [17] in a Volvo D5 optical engine for both non-reactive and reactive conditions, respectively, for different injection strategies. Their measurements were carried out for every $2 \mathrm{CAD}(2.4 \mathrm{kHz})$ which resulted in a relatively long time scale for extraction of cycle-resolved turbulence.

In the present research, the resolution of the PIV system corresponds to $1 \mathrm{CAD}$, to reduce the time scale of measurements and to improve results on cycle-resolved turbulence. Both non-reactive and reactive conditions are studied to better understand injection, mixing, ignition and combustion phenomena for various injection timings. Using skip-fire mode for experiments (one fire per five cycles) gave us this opportunity to compare each fired cycle with its previous motored one. This provided a normalization option to compare results of, for example, different intake temperatures which have different turbulence levels. Furthermore, for the first time, we have compared PIV results for 5-hole and 7-hole injectors to investigate their effect on flow, turbulence and heat release behavior of PPC combustion.

Experiments are performed at Lund University on a VOLVO D5 light-duty optical engine, identical to the one used in our previous study at Eindhoven University of Technology [18]. Operating conditions of this study are also similar to those earlier experiments [18]. The present results are derived from the same experimental campaign as the publications by Wang et al. and Tanov et al. $[\underline{19}, \underline{20}]$.

\section{EXPERIMENTAL SETUP}

\section{Optical Engine}

A schematic of the engine and PIV setup is shown in Figure 1. A cylindrical quartz liner with a height of $25 \mathrm{~mm}$ allows wide optical access through the optical piston and the squish region in side view for PIV measurements. A quartz piston with a realistic bowl geometry, similar to a production-like piston, is used.

Engine and injector specifications are shown in Table 1. Two different Bosch injectors with 5 and 7 injection holes are used. Injector hole diameters are chosen to keep the mean fuel flow rate fixed. EGR is simulated by stoichiometric burning in an external conventional diesel burner. The engine intake air is diluted by the burner exhaust gas to achieve 20 vol- $\%$ oxygen. Intake pressure and temperature are also controlled using a compressor and heater. In-cylinder pressure is measured with a sampling frequency of $24 \mathrm{kHz}$ (every $0.20 \mathrm{CAD}$ ). 


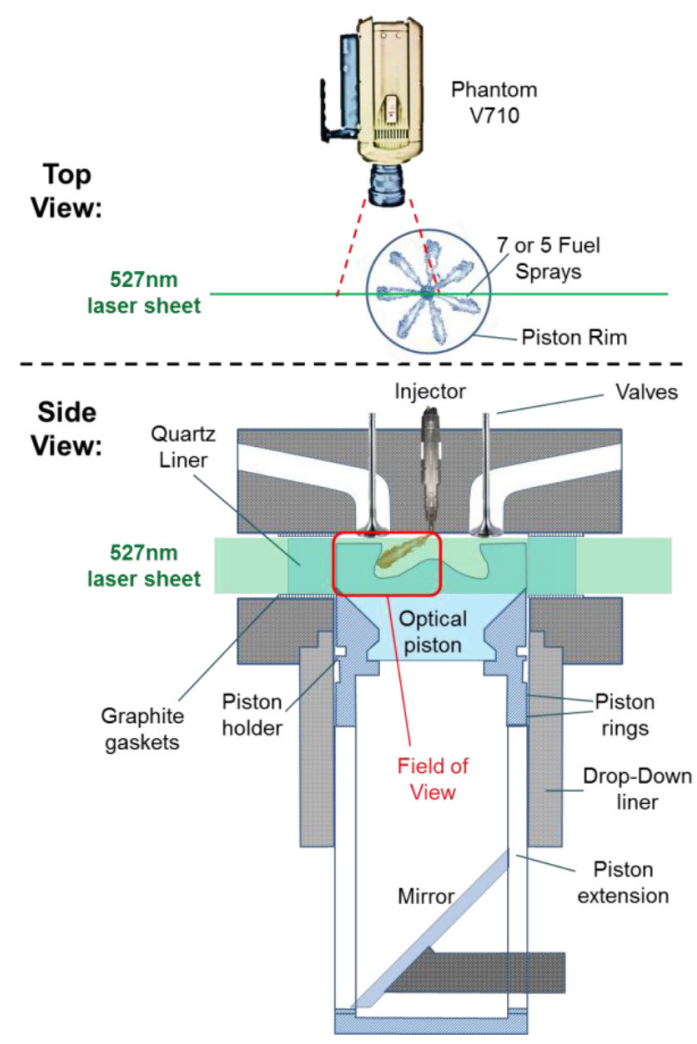

Figure 1. Schematic of the optical engine and the PIV setup.

Table 1. Engine and injector specifications.

\begin{tabular}{|c|c|c|}
\hline Active cylinders & \multicolumn{2}{|l|}{1 out of 5} \\
\hline Cycle & \multicolumn{2}{|l|}{ 4-stroke } \\
\hline Displacement & \multicolumn{2}{|l|}{$480 \mathrm{cc} /$ cylinder } \\
\hline Bore & \multicolumn{2}{|l|}{$81 \mathrm{~mm}$} \\
\hline Stroke & \multicolumn{2}{|l|}{$93.2 \mathrm{~mm}$} \\
\hline Connecting rod length & \multicolumn{2}{|l|}{$147 \mathrm{~mm}$} \\
\hline Compression ratio & \multicolumn{2}{|l|}{$12.3: 1$} \\
\hline Swirl Ratio & \multicolumn{2}{|l|}{2.6 (approximate) } \\
\hline Number of intake valves & \multicolumn{2}{|l|}{2} \\
\hline Number of exhaust valves & \multicolumn{2}{|l|}{2} \\
\hline Injectors type & \multicolumn{2}{|c|}{ Common-rail, solenoid actuated } \\
\hline Number of injector holes & 5 , equally spaced & 7 , equally spaced \\
\hline Orifice diameter & $159 \mu \mathrm{m}$ & $140 \mu \mathrm{m}$ \\
\hline Injector umbrella angle & $140^{\circ}$ & $140^{\circ}$ \\
\hline
\end{tabular}

The heat release analysis of the pressure trace is based on the first law of thermodynamics for a control volume. Heat transfer is considered based on Woschni's model and a crevice model $[\underline{21}, \underline{22}]$. To smooth pressure and heat release traces (noise elimination), a $5^{\text {th }}$ order Hann window function is applied to both of them.

\section{PIV Setup}

Figure 1 shows the high-speed PIV setup used for our measurements. The aim is to measure fluid velocity in a vertical planar cross-section through the centerline of one of the fuel sprays. Titanium dioxide $\left(\mathrm{TiO}_{2}\right)$ powder with an average particle diameter of 2-3 $\mu \mathrm{m}$ and a density of $4260 \mathrm{~kg} / \mathrm{m}^{3}$ is used as PIV seeding. Assuming Stokes flow, the time constant $\left(t_{0}\right)$ characterizing the ability of these particles to follow flow velocity changes is about $30 \mu$ s at TDC thermodynamic conditions (a pressure of 35 bar and a temperature of $900 \mathrm{~K}$ ). This is smaller than the estimated Kolmogorov time scale, so our seeding particles should be able to follow the flow and turbulence quite well. The $\mathrm{TiO}_{2}$ powder has been baked for 24 hours before experiments to avoid particle agglomeration, and is supplied from a cylindrical container fed by a swirling airflow to make a homogeneous airseeding mixture. The seeding stream is controlled by a mass flow meter before mixing with air-EGR at the intake manifold.

A commercial diode-pumped double-cavity Nd:YLF high-speed laser (DualPower $30-1000, \lambda=527 \mathrm{~nm}$ ) is used as PIV light source. The laser is synchronized with the crankshaft encoder to fire a doublepulse light sheet every crank angle degree $(4.8 \mathrm{kHz})$ with an interval of $15 \mu \mathrm{s}$. A light sheet optics unit is used to provide a diverging light sheet with a height of $25 \mathrm{~mm}$ (same height as the optical liner). The light sheet passes through the injector tip with a thickness less than 1 $\mathrm{mm}$. The energy of each laser pulse after all mirrors and optics (just before passing through the engine liner) is $13 \mathrm{~mJ}$.

A high-speed Phantom V710 CMOS camera is used to capture image pairs from side view every crank angle degree. Table 2 shows specifications of the imaging system. Each exposure time comprises one of the laser pulses; a little more time for the second exposure to allow the camera to finalize recording of the first exposure. The field of view is limited to only one side of the piston bowl because of the symmetric geometry of the combustion chamber (see Figure 1).

Table 2. Specifications of the imaging system.

\begin{tabular}{|l|l|}
\hline Camera & Phantom V710 \\
\hline Imaging sensor & 8 bit CMOS \\
\hline Resolution & $976 \times 640$ pixels \\
\hline Frame rate & 4800 pairs $/ \mathrm{s}$ \\
\hline Exposure time of $1^{\text {st }}$ frame & $87 \mu \mathrm{s}$ \\
\hline Exposure time of $2^{\text {nd }}$ frame & $120 \mu \mathrm{s}$ \\
\hline Objective lens & AF Nikkor, $\mathrm{f}=105 \mathrm{~mm}$, visible-light \\
\hline Aperture & $\mathrm{f} / 16$ \\
\hline
\end{tabular}

Imaging the squish region and the piston bowl simultaneously was not feasible. Hence, another set of experiments was performed to capture flow structure in the squish region, under nominally the same experimental conditions. Outcomes of the piston bowl and the squish region are merged to each other whenever needed. Piston bowl measurements are performed from -30 to +30 CAD (ATDC), while squish region measurements are performed from -45 to $+45 \mathrm{CAD}$. Capturing the narrow squish region from -20 to +20 CAD was not possible due to low laser power close to the cylinder head (affected by piston reflection as well) and insufficient resolution of the images in that small region.

\section{Operating Conditions}

The engine is motored at $800 \mathrm{rpm}$ by using a dynamometer. A skip-fire mode is implemented (one fire per five cycles) to reduce thermal and mechanical loads on the optical parts of engine. PRF70 
as a relatively low-reactive fuel, suitable for PPC, is used to extend the ignition delay. The operating conditions of the engine are listed in Table 3.

Table 3. Engine operating conditions .

\begin{tabular}{|l|l|}
\hline Speed & $800 \mathrm{rpm}$ \\
\hline Intake pressure & $1.2 \mathrm{bar} \quad$ (absolute) \\
\hline Intake temperature & $343-423 \mathrm{~K}$ \\
\hline Intake oxygen percentage & $20 \mathrm{vol} \%$ \\
\hline Coolant temperature & $343 \mathrm{~K}$ \\
\hline Fuel & PRF70 \\
\hline Injection pressure & $850 \mathrm{bar}$ \\
\hline Injected fuel mass & $12.4 \mathrm{mg} / \mathrm{cycle}$ \\
\hline CA50 & $7.0 \pm 0.8 \mathrm{CAD}$ ATDC \\
\hline
\end{tabular}

To investigate the effect of SOI on flow characteristics of Partially Premixed Combustion, SOI is swept from -60 to -15 CAD (ATDC) for both injectors. The operating conditions are detailed in Table 4. The injection durations are 2.5 and 2.6 CAD for 5-hole and 7-hole injectors, respectively, to inject the same amount of fuel $(12.4 \mathrm{mg} /$ cycle). Hence, the accumulated heat release is representative for the combustion efficiency of these experimental points as represented in Table 4. Intake temperature is tuned to keep the CA50 constant around 7.0 CAD ATDC.

Table 4. Different injection timings and intake temperatures.

\begin{tabular}{|l|l|l|l|l|}
\cline { 2 - 5 } \multicolumn{4}{l|}{5 -hole Injector } \\
\hline SOI (ATDC) & $\begin{array}{l}\text { Intake } \\
\text { Temperature }\end{array}$ & $\begin{array}{l}\text { SOC (CA05) } \\
\text { (ATDC) }\end{array}$ & $\begin{array}{l}\text { CA50 } \\
\text { (ATDC) }\end{array}$ & $\begin{array}{l}\text { Accumulated } \\
\text { heat release }\end{array}$ \\
\hline$-60.0 \mathrm{CAD}$ & $423 \mathrm{~K}$ & $-3.0 \mathrm{CAD}$ & $6.4 \mathrm{CAD}$ & $206.1 \mathrm{~J} /$ cycle \\
\hline$-25.0 \mathrm{CAD}$ & $393 \mathrm{~K}$ & $-0.8 \mathrm{CAD}$ & $7.3 \mathrm{CAD}$ & $276.2 \mathrm{~J} /$ cycle \\
\hline$-22.5 \mathrm{CAD}$ & $368 \mathrm{~K}$ & $-0.5 \mathrm{CAD}$ & $6.3 \mathrm{CAD}$ & $343.5 \mathrm{~J} /$ cycle \\
\hline$-20.0 \mathrm{CAD}$ & $363 \mathrm{~K}$ & $1.0 \mathrm{CAD}$ & $7.7 \mathrm{CAD}$ & $373.4 \mathrm{~J} /$ cycle \\
\hline$-17.5 \mathrm{CAD}$ & $383 \mathrm{~K}$ & $1.5 \mathrm{CAD}$ & $7.3 \mathrm{CAD}$ & $385.4 \mathrm{~J} /$ cycle \\
\hline$-15.0 \mathrm{CAD}$ & $411 \mathrm{~K}$ & $2.1 \mathrm{CAD}$ & $6.8 \mathrm{CAD}$ & $381.1 \mathrm{~J} /$ cycle \\
\hline & $7-$ hole Injector & \multicolumn{3}{l}{} \\
\hline$-60.0 \mathrm{CAD}$ & $403 \mathrm{~K}$ & $-2.5 \mathrm{CAD}$ & $7.6 \mathrm{CAD}$ & $240.9 \mathrm{~J} /$ cycle \\
\hline$-25.0 \mathrm{CAD}$ & $363 \mathrm{~K}$ & $-1.0 \mathrm{CAD}$ & $7.6 \mathrm{CAD}$ & $319.7 \mathrm{~J} /$ cycle \\
\hline$-22.5 \mathrm{CAD}$ & $353 \mathrm{~K}$ & $-0.5 \mathrm{CAD}$ & $7.1 \mathrm{CAD}$ & $372.9 \mathrm{~J} /$ cycle \\
\hline$-20.0 \mathrm{CAD}$ & $343 \mathrm{~K}$ & $0.2 \mathrm{CAD}$ & $6.5 \mathrm{CAD}$ & $421.3 \mathrm{~J} /$ cycle \\
\hline$-17.5 \mathrm{CAD}$ & $353 \mathrm{~K}$ & $1.4 \mathrm{CAD}$ & $7.3 \mathrm{CAD}$ & $424.2 \mathrm{~J} /$ cycle \\
\hline$-15.0 \mathrm{CAD}$ & $383 \mathrm{~K}$ & $2.1 \mathrm{CAD}$ & $7.2 \mathrm{CAD}$ & $420.8 \mathrm{~J} /$ cycle \\
\hline
\end{tabular}

\section{PIV POST-PROCESSING}

\section{Image Distortion and Adaptive PIV}

Image distortion, caused by the piston bowl geometry, has considerable effects on PIV results and needs to be corrected for. The dewarping procedure includes imaging a reference grid with and without distortion. Based on these two images, a local weighted-mean algorithm is implemented in Matlab to correct all images. This procedure is well described in previous studies $[\underline{9}, \underline{11}, \underline{17}]$.
The commercial PIV software of Dantec Dynamics is used for post-processing of dewarped PIV images based on an adaptive PIV method. This method could iteratively adjust size, shape and orientation of Integrative Area (IA) to cover a wider range of particle movements. The IA size is adjusted from $8 \times 8$ pixels to $64 \times 64$ pixels for our measurements. This adaption is beneficial for PIV measurements in engine conditions with direct injection which includes a wide range of velocities. During injection, fuel droplets of the spray will also scatter the light, so that they, too, can act as seeding particles and are useful for calculation of PIV vectors in those regions to achieve the flow field of the spray [9].

\section{Ensemble Average Velocity and Cycle-Resolved Turbulence}

Ensemble averages of flow fields will provide the overall behavior of in-cylinder flow and would be the first step to understand the mixing process and combustion. In this study, 43 fired cycles are measured for each experimental operating condition. The ensemble average of any velocity component at a given time and location, $\bar{U}_{E A}$, is calculated form:

$$
\bar{U}_{E A}(\theta)=\frac{1}{N} \sum_{i=1}^{N} U(\theta, i)
$$

where $U$ is one of the two instantaneous velocity components, $\theta$ is the crank angle degree, $i$ is the cycle index and $N$ is the number of cycles.

In order to assess the fluctuations in the flow field, we would like to extract a measure for the turbulence from the PIV images. A parameter that is often used to this end is the rms value of the velocity fluctuations, derived from a preferably large number of instantaneous velocity field realizations. In our case, however, this is not an attractive idea, because of the occurrence of cycle-to-cycle variations in individual engine strokes, that also affect the mean flow (relative to which the velocity fluctuations would be defined). We would prefer to use a measure for turbulence within each individual cycle. The high-speed PIV sequences should in principle allow that, a prerequisite being that a mean flow field can be derived. This is not a trivial issue, the more so because we cannot evaluate the out-of-plane velocities. A pragmatic approach is followed here, based on variations in the velocity field over a few crank angles $[\underline{9}, \underline{17}]$ :

$$
u^{\prime}(\theta, i)=\sqrt{\frac{1}{M} \sum_{j=1}^{M}\left[U\left(\theta+\frac{2 j-M-1}{2} \Delta \theta, i\right)-\bar{U}(\theta, i)\right]^{2}}
$$

where $u^{\prime}$ is the cycle-resolved fluctuating velocity component, $\theta$ is the crank angle degree, $i$ is the cycle index, $\Delta \theta$ is the CAD step size (1 CAD for our measurements), $j$ is a counter and $M$ is the total number of crank angle degrees in the considered time window. In our study $M$ equals five, implying that, for any $\theta$, the velocity fields of five CADs, $\theta+\Delta \theta$ are considered, with $\Delta \theta=-2,-1,0,+1,+2 \mathrm{CAD}$. The mean velocity at the center $\mathrm{CAD}$ is calculated from: 


$$
\bar{U}(\theta, i)=\frac{1}{M} \sum_{j=1}^{M} C(j) \cdot U\left(\theta+\frac{2 j-M-1}{2} \Delta \theta\right)
$$

where $C(j)$ is a sine weight factor:

$$
C(j)=\frac{\sin \left(\frac{j}{M+1} \pi\right)}{\sum_{j=1}^{M} \sin \left(\frac{j}{M+1} \pi\right)} \quad j=1,2, \ldots, M .
$$

Obviously: $\sum_{j=1}^{M} \mathrm{C}(j)=1$.

Our measure for turbulence is essentially the rms-value of the velocity changes over a few crank angles. We realize the shortcomings of this parameter, for instance its being sensitive to the structure of the out-of-plane flow field, but expect it to at least scale with the real amount of turbulence present in the instantaneous flow field. In our study, $M$ equals five since the time scale of the phenomena in the engine operating conditions cannot be bigger than a few crank angle degrees. The absolute fluctuating velocity at a given time and location $\left(U^{\prime}(\theta, i)\right)$ is calculated from the square root of the sum of the squares of the fluctuating velocity components:

$$
U^{\prime}(\theta, i)=\sqrt{u_{x}^{\prime}(\theta, i)^{2}+u_{y}^{\prime}(\theta, i)^{2}}
$$

where $u_{x}^{\prime}(\theta, i)$ and $u_{y}^{\prime}(\theta, i)$ are fluctuating velocity components calculated from Eq. (2). The fluctuating velocity at a given CAD is determined later by averaging the absolute fluctuating velocities of all positions in the piston bowl and all cycles.

For presenting turbulence results, the fluctuating velocity (Eq. (5)) at a given CAD is normalized by the mean fluctuating velocity of the previous motoring cycle from -30 to +30 CAD. This is called the turbulence level. Motoring measurements are performed based on the skip-fire mode, meaning that for each fire cycle, the PIV images of the previous motoring cycles are recorded as well. This normalization method allows to compare turbulence levels of different operating conditions with different intake temperatures (Table 4). The same averaging and normalization method is used to calculate the normalized velocity at a given CAD.

\section{RESULTS AND DISCUSSION}

PIV measurements are processed in combination with heat release analysis of pressure traces to study effects of flow characteristics on mixing and combustion behavior. Turbulence has a significant effect on mixing, ignition timing and duration of PPC. Hence, turbulence is the main focus of this study. In this section, the flow field of PPC is discussed first. Next, effects of injection timing on flow and heat release characteristics are investigated. Reactive and non-reactive cases are compared, and finally, differences between 5-hole and 7-hole injectors are examined.

\section{Flow Characteristics of PPC: From SOI to End of Combustion}

Typical curves for pressure trace, rate of heat release and turbulence level of PPC combustion are illustrated in Figure 2 (SOI: -17.5 CAD, 7-hole injector). The magnitude of the error bars is similar in other experimental results. Hence, for the sake of clarity, they are not included in the following graphs.

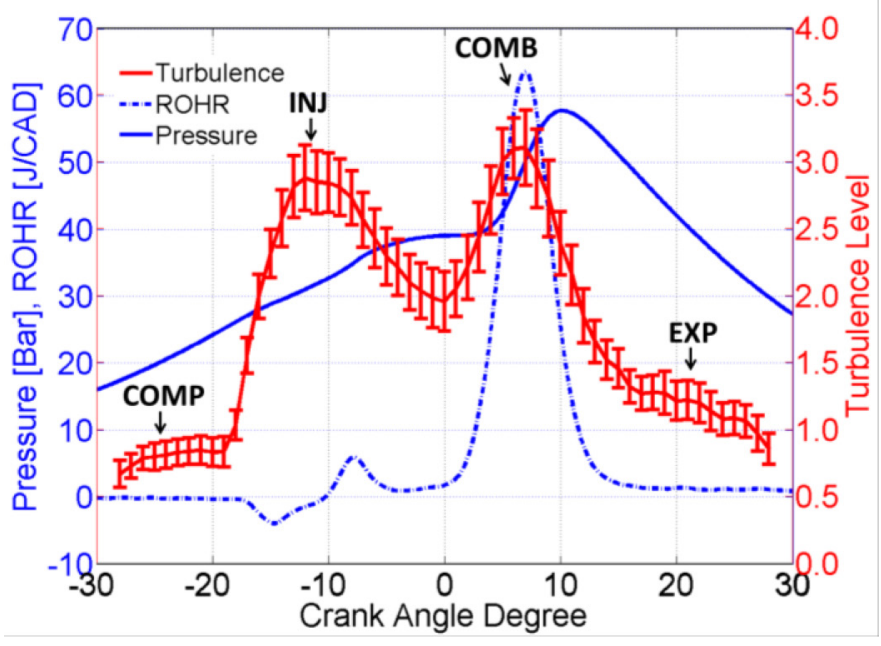

Figure 2. Pressure trace, rate of heat release and turbulence level behaviors of PPC for injection timing at -17.5 CAD ATDC using a 7-hole injector.

Various phenomena which affect flow characteristics in the combustion chamber occur from -30 to $+30 \mathrm{CAD}$, including compression, injection, mixing during ignition delay, combustion and expansion. Each step is detailed below in combination with the velocity fields shown in Figure 3 . There is a small area close to the piston bowl rim in which the laser sheet was reflected, causing unreliable PIV data. That is the reason velocity vectors are absent in this region in Figure 3 .

\section{Compression}

By approaching TDC from -30 CAD, the flow is mainly governed by upward piston motion and the flow velocity decreases as the piston velocity decreases. This is clearly visible in Figure 3 by comparing velocity directions and magnitudes at -26 and -18 CAD. However, the turbulence level is increasing upon approaching TDC (see Figure 2). The upward motion of the piston compresses the flow in the squish region and pushes it into the piston bowl. The interaction of this squish flow with swirl motion enhances the turbulence level in the combustion chamber []].

\section{Injection}

There is a little hydraulic delay causing the spray to reach the piston bowl at -16 CAD for SOI of -17.5 CAD ATDC (see Figure 3). The flow field at $-16 \mathrm{CAD}$ shows that the spray penetrates the piston bowl and at $-15 \mathrm{CAD}$ the spray has stabilized and caused a clockwise vortex, governed by the piston bowl geometry. Another significant flow structure which is created during injection is air entrainment, large upward vectors below the injector tip especially at the beginning of the injection. This air entrainment behavior is exactly 
similar to that seen and discussed by Zegers et al. [15]. The spray velocity is higher than the piston velocity and the mean velocity in the combustion chamber. Hence, the mean velocity (in the chosen PIV plane) dramatically increases by the injection. It also effects the turbulence level within the combustion chamber, increasing it by a factor of 2 to 4 (depending on the injection timing).

\section{Ignition Delay}

The vortex inside the piston bowl, driven by the spray, persists during ignition delay. By approaching TDC, the flow in the squish region is pushed into the piston bowl, supporting the clockwise vortex $[\underline{9}, \underline{12}$, $\underline{14}, 17]$. This vortex structure improves the mixing process, even though turbulence level and mean velocity decrease after the end of injection (see Figures 2 and $\underline{3}$ ). The swirl motion can also cause a velocity and turbulence drop in the observation plane [23]. However, different decreasing rates of velocity and turbulence level shown in $\underline{\text { Figures } 5}$ and $\underline{6}$ for different injection timings prove that this cannot be only caused by the swirl motion since it was the same for all cases. This velocity and turbulence drop decreases the mixing efficiency until the start of combustion.

\section{Combustion}

Strong turbulence during combustion and auto-ignition causes random behavior in the flow field inside the piston bowl. Hence, the mean flow field does not show a clear flow structure. Comparing flow fields at +6 and +7 CAD indicates that high mean velocity regions move through the piston bowl, showing the motion of the combustion region $[\underline{9}, \underline{17}]$. Mean velocity and turbulence levels during combustion follow the heat release rate quite well, meaning that an increase in the rate of heat release results in an increase of mean velocity and turbulence level and vice versa.

\section{Expansion}

After the end of combustion, the flow is again governed by piston downward motion, and the mean velocity increases as the piston velocity increases. The inner wall of the piston bowl at the right side

Compression:

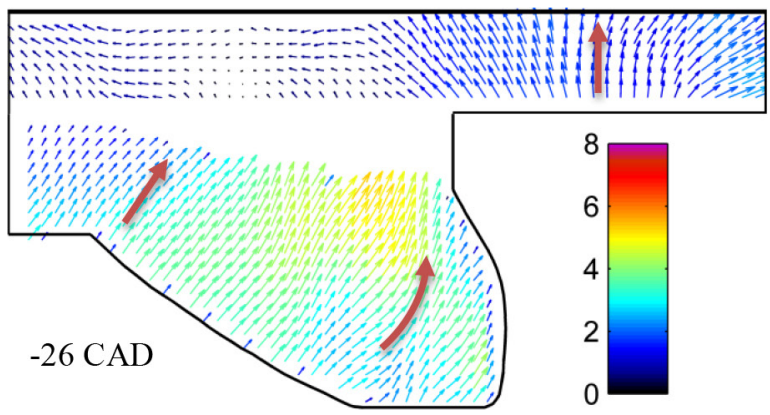

has the highest effect on the flow field, by trapping and pushing the flow downward (Figure 3 ). By the expansion of the squish region, flow goes from the piston bowl into the squish region (see Figure 3 at $+26 \mathrm{CAD})[\underline{9}, \underline{12}, \underline{14}, \underline{17}]$.

\section{Effects of Injection Timing}

Injection timing is one of the main factors to control combustion phasing and the smoothness of heat release rate. Ignition delay (= mixing time) depends on the injection timing, and the amount of combustion stratification is governed by that. In this study, the combustion phasing is kept constant at $7 \pm 0.7 \mathrm{CAD}$ ATDC, meaning that later injection causes less mixing time (ignition delay). However, mixing process from SOI until -3 CAD (minimum SOC for all cases) is not affected by combustion, and can be investigated from a mixing efficiency point of view. Experimental results presented in this section are obtained with a 7-hole injector and based on operating conditions mentioned in Table. 4.

Figure 4 shows the heat release rate behavior for 4 different injection timings between -60 and -15 CAD ATDC. There are three main parameters affecting the smoothness of heat release rate: mixture temperature, mixture homogeneity and the turbulence level at SOC. From Table 4 it follows that the intake temperature for SOI -15 CAD is $40 \mathrm{~K}$ higher than that for $\mathrm{SOI}-20 \mathrm{CAD}$, causing a sharper rise of the ROHR in the former case. Less mixing time for SOI -15 CAD compared to all other points can increase the mixture stratification and induce local equivalence ratios closer to stoichiometry, resulting in the sharpest heat release rate. The relatively high turbulence level can also speed up the combustion process resulting in the sharpest heat release rate as will be discussed in detail in the next section. However, comparing intake temperatures of SOI -20 CAD (343 K) with SOI -25 and $-60 \mathrm{CAD}$ (363 and $403 \mathrm{~K}$, respectively) does not explain the smoothness of ROHR for these cases as the higher intake temperature has nevertheless led to smoother ROHR. Hence, mixture homogeneity and turbulence are the main controlling factors of

Figure 3. Mean flow field at different crank angle degrees for SOI at -17.5 CAD ATDC using the 7-hole injector (units in $\mathrm{m} / \mathrm{s}$ ). 
Injection:
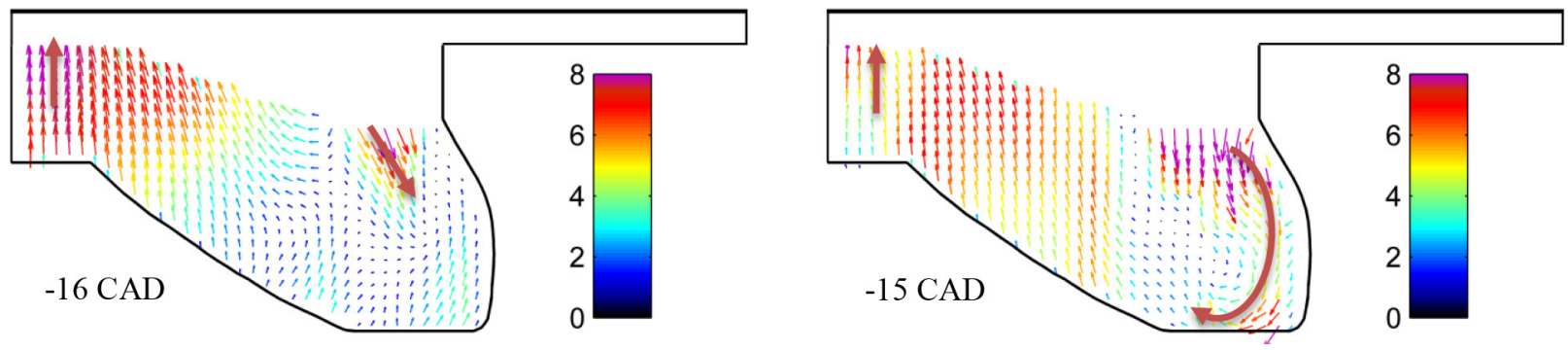

Approaching TDC:
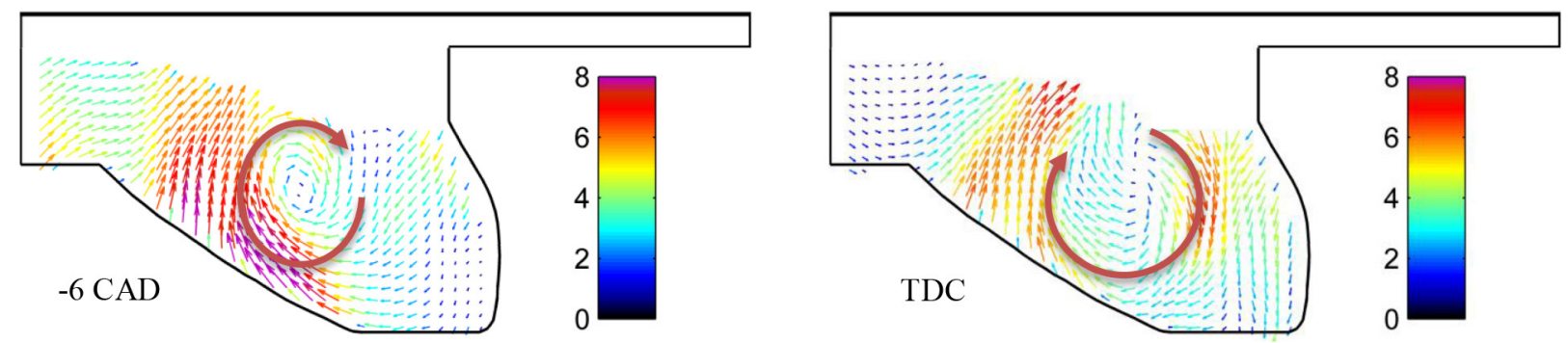

Combustion:
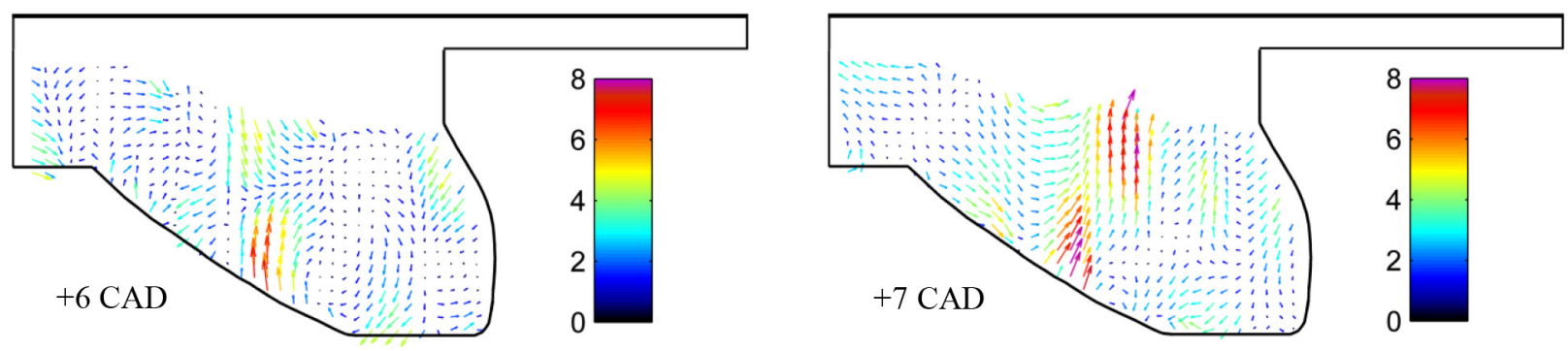

Expansion:
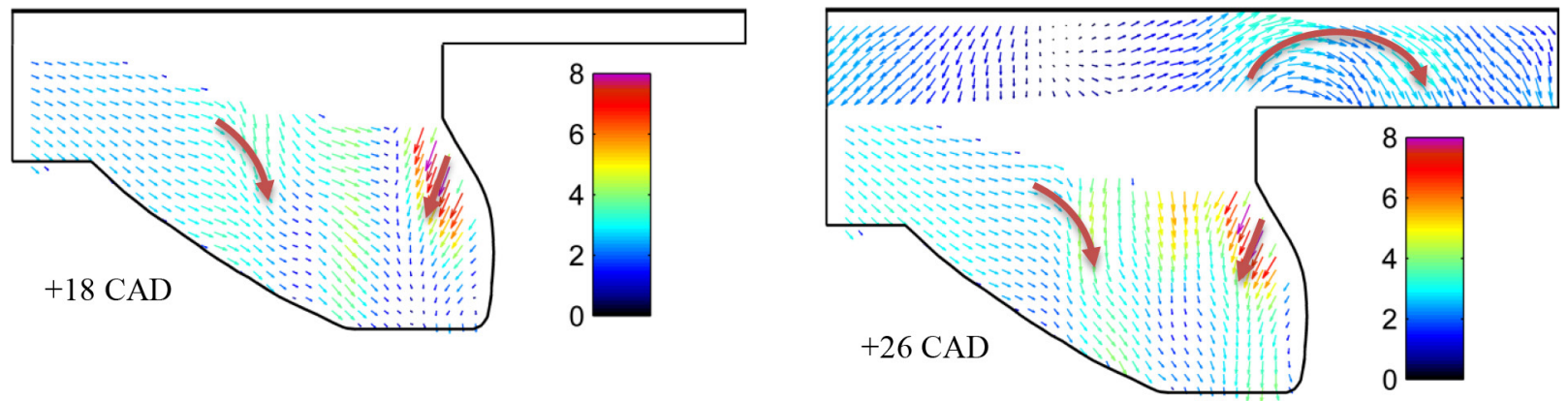

Figure 3. (cont.) Mean flow field at different crank angle degrees for SOI at -17.5 CAD ATDC using the 7-hole injector (units in m/s).

ROHR behavior in our experiments. It should be mentioned that the experiment with SOI -60 CAD has lower combustion efficiency (see Table 4), attributable to a large amount of fuel trapped in the crevice volumes [18].

Mixture stratification is mainly governed by mixing duration and mixing efficiency. Increased mixing duration provides more homogeneity if the mixing efficiencies would be similar for all cases. In principle, stronger turbulence will increase mixing. With the PIV results of velocity and turbulence level, the mixing efficiency can be discussed in more detail. Figures 5 and $\underline{6}$ demonstrate mean velocity and turbulence level as a function of crank angle for different injection timings.

These results show that later injection leads to higher mean velocity and turbulence level inside the piston bowl. This behavior is probably caused by the geometry and the position of the piston bowl relative to the spray targeting. The decay rates of mean velocity and turbulence level after the end of injection are also higher for later injections. Nevertheless, higher turbulence levels are achieved at SOC for later 
injections, speeding up the combustion process. On the other hand, the mixing efficiency would be higher for later injections based on the higher velocities and turbulence levels, which would be a trade off with mixing duration to affect mixture homogeneity. Based on our operating conditions, effects of mixing duration and the turbulence level at SOC seem to overcome the effects of mixing efficiency on charge stratification, since steeper heat release rates are achieved for later injections with shorter ignition delays. Our previous study [18] shows that combustion stratification drops upon retarding the SOI from -25 to -15 CAD ATDC for similar operating conditions. In those experiments CA50 was not kept constant and these different injection timings had almost the same ignition delays and intake temperatures. Hence, the only parameter affecting the combustion homogeneity was mixing efficiency, which can be explained by these new PIV results, proving higher mixing efficiencies by later injections.

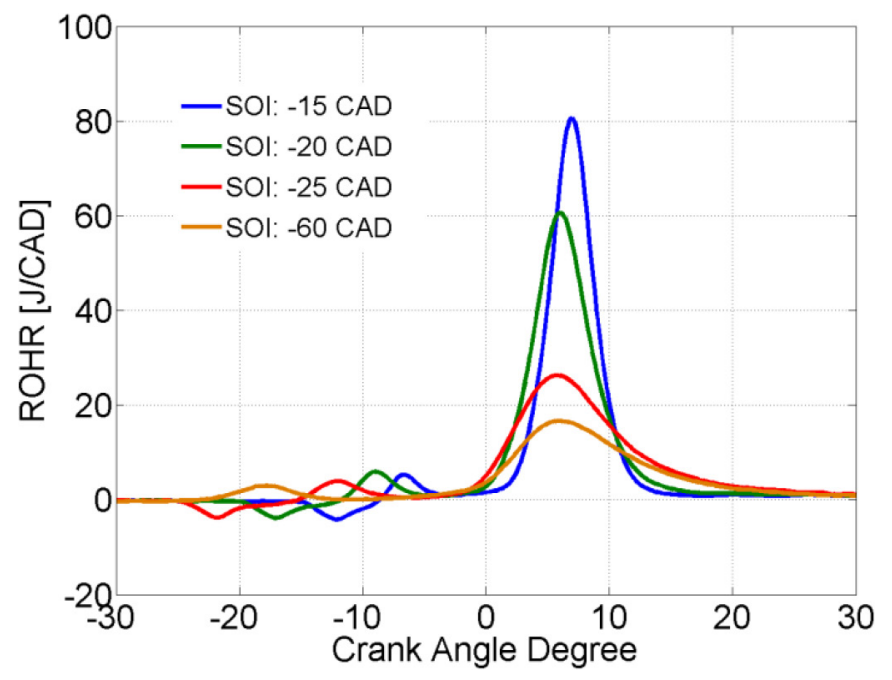

Figure 4. Heat release rate of different injection timings for 7-hole injector.

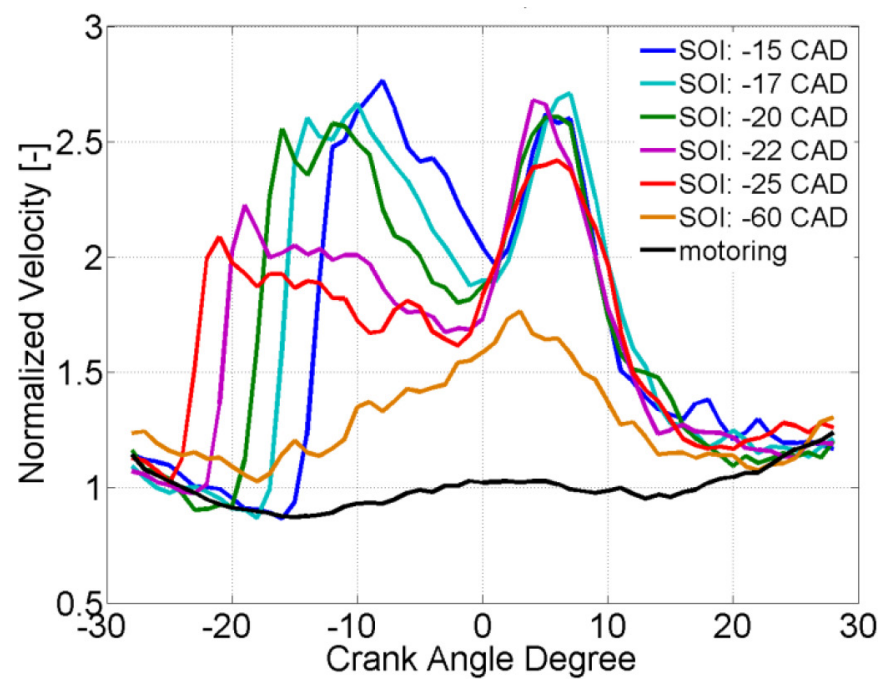

Figure 5. Normalized velocity versus crank angle degrees for different injection timings.

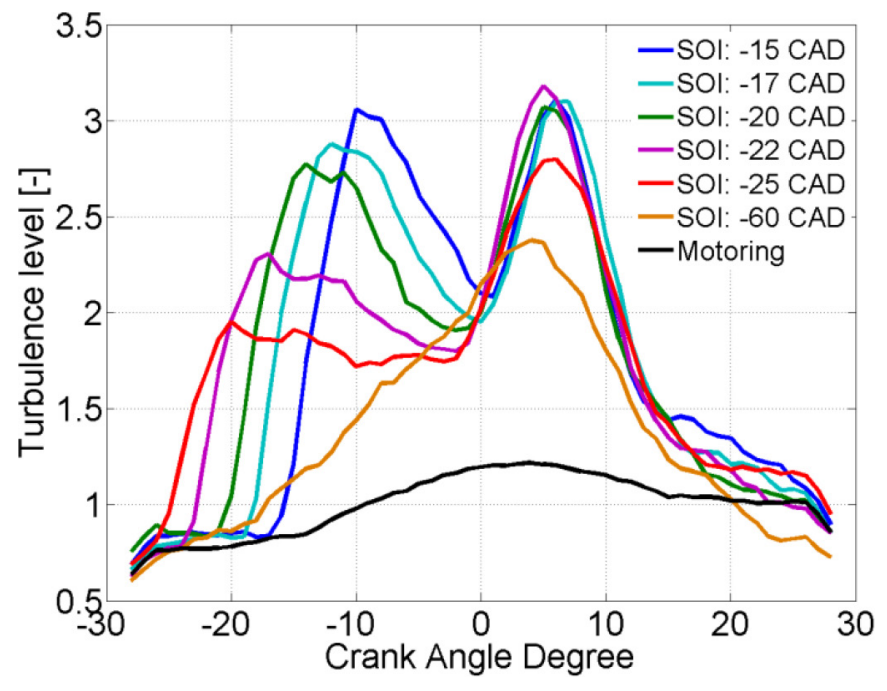

Figure 6. Mean turbulence level versus crank angle degrees for different injection timings.

In contrast with the low velocity magnitudes of the mean flow field shown in Figure 3 at +6 and +7 CAD (around CA50), the mean velocity magnitudes derived from individual cycles show a significant increase during combustion (see Figure 5). Velocity vectors of individual cycles during auto-ignition are large and directionally unstructured. Hence, their mean magnitudes are large while the mean flow field (average of velocity vectors over 43 cycles) shows small velocity vectors.

For SOI -60 CAD, the turbulence and velocity behaviors inside the piston bowl were not accessible during injection. As expected, the flow field does not show any spray-related features, and we will omit the results for this SOI-case in the remainder.

\section{Injection-Driven vs Combustion-Driven Turbulence}

Comparing flow characteristics of reactive and non-reactive operating conditions (20 and 0 vol- $\%$ volumetric oxygen, respectively) allows to distinguish between injection-driven and combustion-driven flow characteristics. Figure 7 compares the turbulence level of reactive and non-reactive cycles for three different injection timings using a 5-hole injector. Clearly, the second bump in the turbulence level is combustion-driven turbulence which is absent in non-reactive cycles.

The combustion-driven turbulence level can be estimated by subtraction of the non-reactive turbulence level from the reactive one from TDC to +30 CAD where the combustion has ended. Injectiondriven turbulence level, on the other hand, can be determined by subtraction of motoring turbulence level from the fired one up to TDC (start of combustion). TDC is chosen as a reference point for separation of combustion from mixing, since the average CA05 for our experiments is at TDC. The injection-driven turbulence level at SOC is determined by averaging of injection-driven turbulence level 
from -5 CAD to TDC. Figure 8 (a) shows the injection-driven turbulence level at SOC as a function of injection timing. Obviously, by retarding the injection, the injection-driven turbulence level at SOC is linearly increasing. Figure 8 (b) demonstrates a linear decrease of combustion-driven turbulence level by later injection. Note that the maximum combustion-driven turbulence level does not change much for different injection timings (see Figures 5 and 7 ). However, the duration of combustion has a considerable effect on the mean combustion-driven turbulence level which is averaged from TDC to +30 CAD.

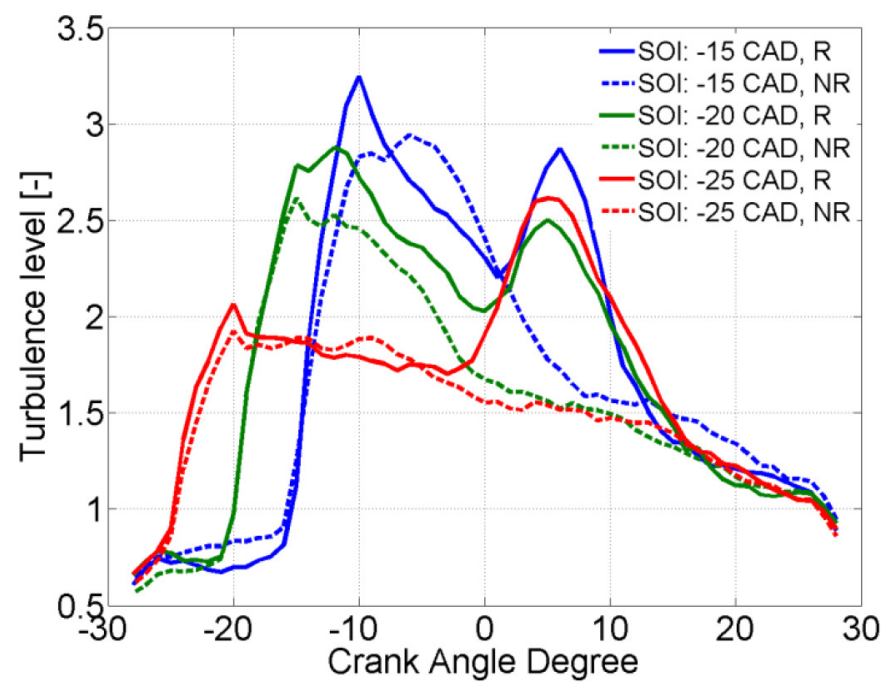

Figure 7. Comparison of reactive and non-reactive turbulence level behaviors for different injection timings.
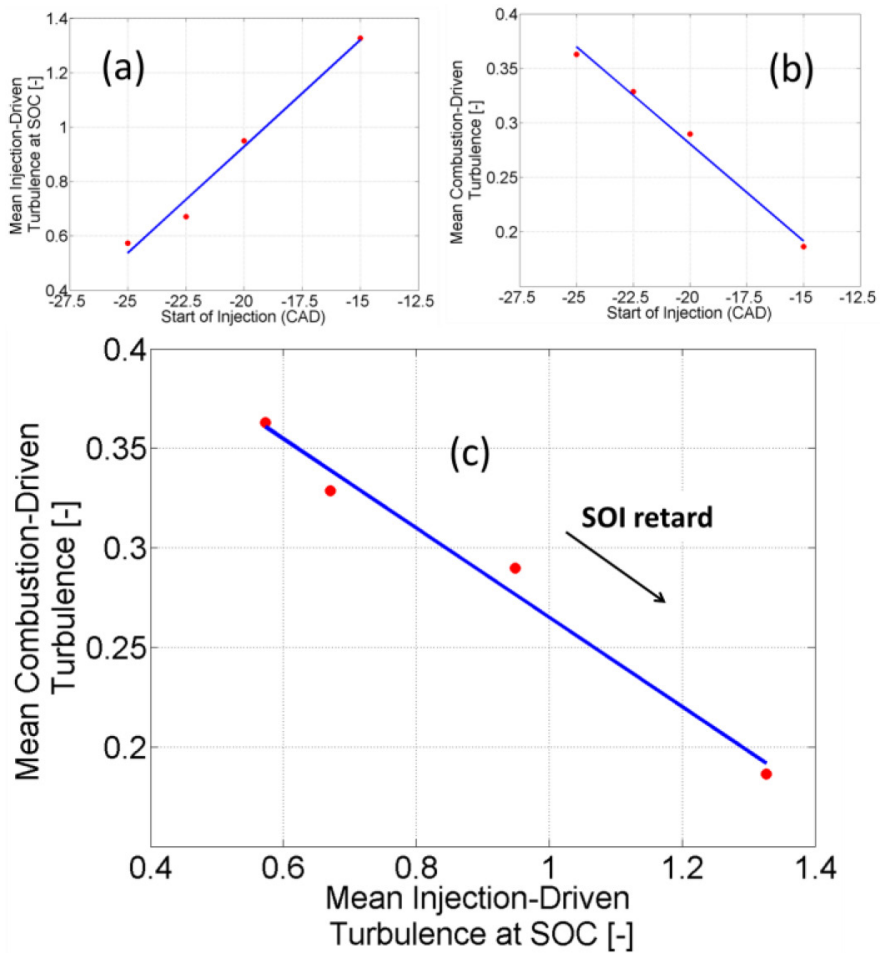

Figure 8. (a): Mean of the injection-driven turbulence level at SOC as function of SOI. (b): Mean of the combustion-driven turbulence level as a function of start of injection. (c): Mean of the combustion-driven turbulence level as a function of the injection-driven turbulence level at SOC.
The mean combustion-driven turbulence level as a function of the injection-driven turbulence level at SOC is shown in Figure 8 (c); obviously, they are linearly related as well. Higher injection-driven turbulence level at start of combustion would speed up the combustion process [24] and consequently the mean combustion-driven turbulence level decreases linearly. Note that the effect of swirl motion is not seen in our measurements, meaning that the center of the combustion cloud during the main heat release is not within the spray cross-section plane which we have measured. Hence, we recommend using volumetric simulations to better understand the effects of injection-driven turbulence level on the combustion-driven one.

\section{Comparison of 7-Hole and 5-Hole Injectors}

The 5-hole injector has a bigger orifice diameter $(159 \mu \mathrm{m})$ compared to the 7-hole injector $(140 \mu \mathrm{m})$, ensuring almost equal spray velocities but higher mass flow rate per spray for the 5-hole injector. Figure 9 compares the turbulence levels for these two injectors for different injection timings. During the mixing time there are only small differences between the two injectors, the 5-hole injector may cause a slightly larger increase of the turbulence, but this lies within the range of error bars (see Figure 2 for the uncertainty range of turbulence level). As a conclusion, we see a similar injection-driven turbulence level per individual spray for both 5-hole and 7-hole injectors.

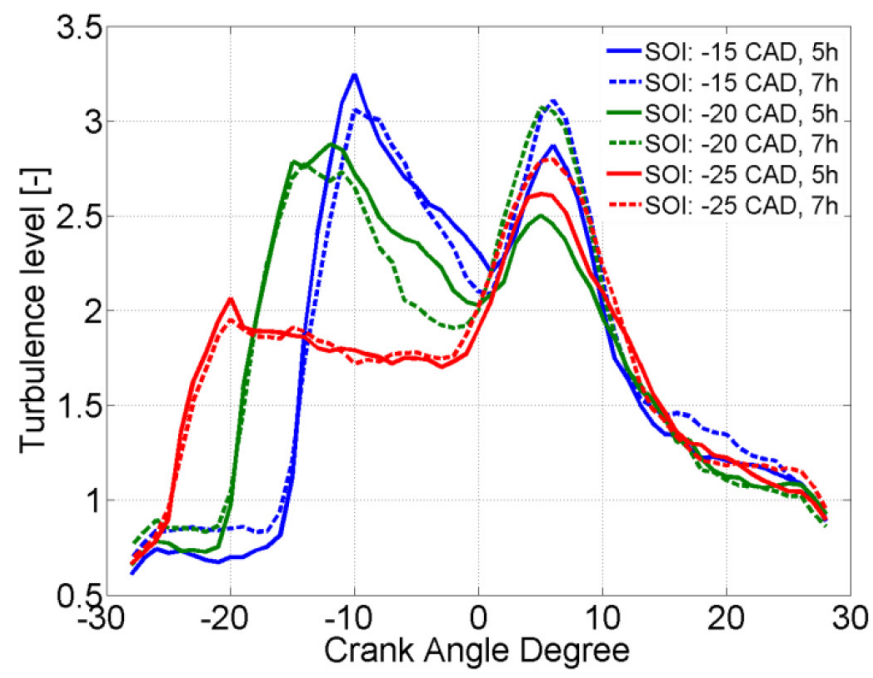

Figure 9. Comparison of turbulence level behaviors of 5-hole and 7-hole injectors for different injection timings.

Sharper heat release rates are achieved by using the 7-hole injector, as shown in Figure 10, even though their intake temperatures are a little bit less compared to the ones of 5-hole injector (see Table 4). Hence, the heat release rate behaviors have to be interpreted from homogeneity and flow characteristics points of view. The results also show that combustion efficiency for the 7-hole injector is a little higher than for the 5-hole injector (see Table 4). Individual sprays of both nozzles behaving similarly, the total turbulence produced by a nozzle will scale with the number of holes. Hence, the 7-hole injector causes more turbulence and kinetic energy in the piston bowl compared to the 5-hole injector. Consequently, we can expect less stratification of both fuel and combustion for the 7-hole injector. Higher turbulence levels at SOC will result in faster combustion as 
discussed in previous section. Hence, sharper heat release rates are achieved for a 7-hole injector, with a better mixing and higher combustion efficiencies.

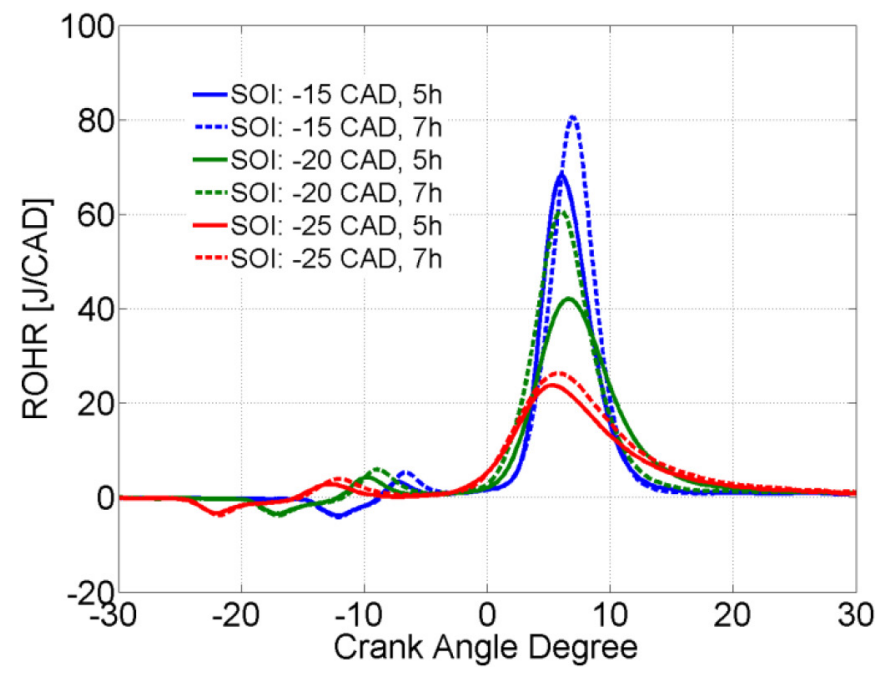

Figure 10. Comparison of heat release rate of 5-hole and 7-hole injectors for different injection timings.

The maximum combustion-driven turbulence level for the 7-hole injector is noticeably higher than for the 5-hole injector. This difference cannot be explained by sharper heat release rates since the combustion-driven turbulence level results presented in Figure 5 show that the maximum combustion-driven turbulence level is almost the same for different ROHR behaviors. Although not visible in our results, it is hypothesized that interactions are stronger between 7 combustion clouds (7-hole injector) compared to 5 ones (5-hole injector), resulting in higher turbulence level, heat release rate and combustion efficiency.

\section{SUMMARY/CONCLUSIONS}

The objective of this study was to measure flow characteristics of PPC from injection to the end of combustion. High-speed PIV measurements were performed in a light-duty optical engine in a vertical planar cross-section in the piston bowl and the squish region containing the centerline of one of the sprays. The flow field, mean velocity and turbulence level for different injection timings were analyzed. Injection-driven and combustion-driven turbulence level were determined based on reactive and non-reactive conditions. Finally, flow characteristics of two different injectors with 5 and 7 holes were compared to investigate their effects on PPC.

The following is concluded based on our results:

Flow characteristics of PPC:

- During injection, the turbulence level noticeably increases by 2 to 4 times depending on the injection timing. The vortex inside the piston bowl, driven by the spray, persists during the ignition delay period.

- After the end of injection, turbulence level and mean velocity decrease, which decreases the mixing efficiency until the start of combustion.
- During combustion, mean velocity and turbulence level follow the heat release rate quite well.

- After the end of combustion, flow features are governed by the piston downward motion.

Effects of injection timing:

- Later injection causes higher mean velocity and turbulence level inside the piston bowl, and consequently higher mixing efficiency.

- Later injection causes higher injection-driven turbulence at SOC, and consequently sharper heat release rate.

- Later injection results in less combustion-driven turbulence.

5-hole vs 7-hole injector:

- The injection-driven turbulence per individual spray is similar for both 5-hole and 7-hole injectors, indicating identical spray behavior.

- The 7-hole injector leads to sharper heat release rates, better mixing and higher combustion efficiency compared to the 5-hole injector.

- The 7-hole injector produces higher combustion-driven turbulence than the 5-hole injector.

\section{REFERENCES}

1. Manente, V., Johansson, B., and Cannella, W., "Gasoline partially premixed combustion, the future of internal combustion engines?, " Int. J. Engine Res. 12(3):194-208, 2011, doi:10.1177/1468087411402441.

2. Hardy, W. and Reitz, R., "An Experimental Investigation of Partially Premixed Combustion Strategies Using Multiple Injections in a HeavyDuty Diesel Engine," SAE Technical Paper 2006-01-0917, 2006, doi: 10.4271/2006-01-0917.

3. Noehre, C., Andersson, M., Johansson, B., and Hultqvist, A., "Characterization of Partially Premixed Combustion," SAE Technical Paper 2006-01-3412, 2006, doi:10.4271/2006-01-3412.

4. Izadi Najafabadi, M., Somers, B., and Nuraini, A., "Validation of a Reduced Chemical Mechanism Coupled to CFD Model in a 2-Stroke HCCI Engine," SAE Technical Paper 2015-01-0392, 2015, doi: $10.4271 / 2015-01-0392$.

5. Neely, G., Sasaki, S., and Leet, J., "Experimental Investigation of PCCIDI Combustion on Emissions in a Light-Duty Diesel Engine," SAE Technical Paper 2004-01-0121, 2004, doi:10.4271/2004-01-0121.

6. Kalghatgi, G., Risberg, P., and Ångström, H., "Advantages of Fuels with High Resistance to Auto-ignition in Late-injection, Low-temperature, Compression Ignition Combustion," SAE Technical Paper 2006-013385, 2006, doi: 10.4271/2006-01-3385.

7. Yin, L., Ingesson, G., Shamun, S., Tunestal, P. et al., "Sensitivity Analysis of Partially Premixed Combustion (PPC) for Control Purposes," SAE Technical Paper 2015-01-0884, 2015, doi:10.4271/2015-01-0884.

8. Hanson, R., Splitter, D., and Reitz, R., "Operating a Heavy-Duty Direct-Injection Compression-Ignition Engine with Gasoline for Low Emissions," SAE Technical Paper 2009-01-1442, 2009, doi: $10.4271 / 2009-01-1442$.

9. Wang, Z., Tanov, S., Wang, H., Richter, M. et al., "High-Speed Particle Image Velocimetry Measurement of Partially Premixed Combustion (PPC) in a Light Duty Engine for Different Injection Strategies," SAE Technical Paper 2015-24-2454, 2015, doi:10.4271/2015-24-2454.

10. Johansson, B., "Influence of the Velocity Near the Spark Plug on Early Flame Development," SAE Technical Paper 930481, 1993, doi:10.4271/930481.

11. Miles, P., Megerle, M., Sick, V., Richards, K. et al., "The Evolution of Flow Structures and Turbulence in a Fired HSDI Diesel Engine," SAE Technical Paper 2001-01-3501, 2001, doi:10.4271/2001-01-3501. 
12. Miles, P., Megerle, M., Hammer, J., Nagel, Z. et al., "Late-Cycle Turbulence Generation in Swirl-Supported, Direct-Injection Diesel Engines," SAE Technical Paper 2002-01-0891, 2002, doi:10.4271/2002$\underline{01-0891}$

13. Miles, P.C., Collin, R., Hildingsson, L., Hultqvist, A., Andersson, Ö., "Combined measurements of flow structure, partially oxidized fuel, and soot in a high-speed, direct-injection diesel engine," Proc. Combust. Inst. 31(2):2963-2970, doi:10.1016/j.proci.2006.07.231

14. Miles, P.C., Hildingsson, L., Hultqvist, A., "The influence of fuel injection and heat release on bulk flow structures in a direct-injection, swirl-supported diesel engine", Exp. Fluids 43(2-3): 273, 2007, doi:10.1007/s00348-007-0281-7.

15. Zegers, R.P.C., Luijten, C.C.M., Dam, N. J., De Goey, L.P.H., "Pre- and post-injection flow characterization in a heavy-duty diesel engine using high-speed PIV, " Exp. Fluids 53(3):731-746, 2012, doi:10.1007/s00348012-1323-3.

16. http://www.dantecdynamics.com/particle-image-velocimetry

17. Tanov, S., Wang, Z., Wang, H., Richter, M. et al., "Effects of Injection Strategies on Fluid Flow and Turbulence in Partially Premixed Combustion (PPC) in a Light Duty Engine," SAE Technical Paper 201524-2455, 2015, doi: 10.4271/2015-24-2455.

18. Izadi Najafabadi, M., Dam, N., Somers, B., and Johansson, B. "Ignition Sensitivity Study of Partially Premixed Combustion by Using Shadowgraphy and $\mathrm{OH}^{*}$ Chemiluminescence Methods," SAE Technical Paper 2016-01-0761, 2016, doi:10.4271/2016-01-0761.

19. Wang, H.; Tanov, S.; Izadi Najafabadi, M.; Wang, Z.; Johansson, B., "Time-resolved in-cylinder PIV measurement in a light duty optical engine under PPC conditions," Lisbon 2016 International Symposium on the Application of Laser and Imaging Techniques to Fluid Mechanics, 2016.

20. Tanov, S., Johansson, B., Izadi Najafabadi, M., Wang, H., "Analyzing Of In-Cylinder Flow Structures And Cyclic Variations Of Partially Premix Combustion In A Light Duty Engine," FISITA 2016 World Automotive Congress, F2016-ESYF-005, 2016.

21. Woschni, G. and Fieger, J., "Determination of Local Heat Transfer Coefficients at the Piston of a High Speed Diesel Engine by Evaluation of Measured Temperature Distribution," SAE Technical Paper 790834, 1979, doi:10.4271/790834.

22. Gatowski, J., Balles, E., Chun, K., Nelson, F. et al., "Heat Release Analysis of Engine Pressure Data," SAE Technical Paper $\underline{841359}$, 1984, doi:10.4271/841359.

23. Miles P C, "Turbulent flow structure in direct-injection, swirl-supported diesel engines" in Flow and combustion in reciprocating engines, ed. Arcoumanis C. and Kamimoto T., Springer Berlin, Heidelberg Germany (2009).

24. Tabaczynski Rodney J., "Turbulence and turbulent combustion in sparkignition engines," Prog. Energy Combust. Sci. 2(3): 143-165, 2003, doi:10.1016/0360-1285(76)90010-1.

\section{CONTACT INFORMATION}

\author{
M. Izadi Najafabadi \\ Multiphase \& Reactive Flows \\ Department of Mechanical Engineering \\ Eindhoven University of Technology \\ GEM-N 1.21, De Rondom 70 \\ 5612 AP, Eindhoven \\ The Netherlands \\ $\mathrm{T}+31402475995$ \\ $\mathrm{F}+31402433445$ \\ M.Izadi.Najafabadi@tue.nl \\ www.tue.nl/MRF
}

\section{ACKNOWLEDGMENTS}

The research leading to these results has received funding from the People Programme (Marie Curie Actions) of the European Union's Seventh Framework Programme FP7/2007-2013/ under REA grant agreement $n^{\circ} 607214$. The authors would like to acknowledge Dantec Dynamics for providing the PIV setup and post-processing support.

\section{DEFINITIONS/ABBREVIATIONS}

ATDC - After top dead center
CA50 - Crank angle at $50 \%$ burn
CAD - Crank angle degree
CMOS - Complementary metal-oxide semiconductor
FOV - Field of view
fps - Frames per second
HCCI - Homogeneous Charge Compression Ignition
LDA - Laser Doppler Anemometry
SOC - Start of combustion
SOI - Start of injection
PIV - Particle Image Velocimetry
PPC - Partially Premixed Combustion
PRF - Primary Reference Fuel
rms - Root mean square
ROHR - Rate of heat release
rPm - Revolutions per minute

